Article

\title{
Construction of A New Dose-Response Model for Staphylococcus aureus Considering Growth and Decay Kinetics on Skin
}

\author{
Elaheh Esfahanian ${ }^{1}$, Umesh Adhikari ${ }^{1}$, Kirk Dolan ${ }^{1,2}$ and Jade Mitchell ${ }^{1, *(D)}$ \\ 1 Department of Biosystems and Agricultural Engineering, Michigan State University, East Lansing, MI 48824, \\ USA; esfahan3@msu.edu (E.E.); adhika12@msu.edu (U.A.); dolank@anr.msu.edu (K.D.) \\ 2 Department of Food Science and Human Nutrition, Michigan State University, East Lansing, MI 48824, USA \\ * Correspondence: jade@msu.edu
}

Received: 16 October 2019; Accepted: 19 November 2019; Published: 21 November 2019

\begin{abstract}
In order to determine the relationship between an exposure dose of Staphylococcus aureus (S. aureus) on the skin and the risk of infection, an understanding of the bacterial growth and decay kinetics is very important. Models are essential tools for understanding and predicting bacterial kinetics and are necessary to predict the dose of organisms post-exposure that results in a skin infection. One of the challenges in modeling bacterial kinetics is the estimation of model parameters, which can be addressed using an inverse problem approach. The objective of this study is to construct a microbial kinetic model of $S$. aureus on human skin and use the model to predict concentrations of $S$. aureus that result in human infection. In order to model the growth and decay of $S$. aureus on skin, a Gompertz inactivation model was coupled with a Gompertz growth model. A series of analyses, including ordinary least squares regression, scaled sensitivity coefficient analysis, residual analysis, and parameter correlation analysis were conducted to estimate the parameters and to describe the model uncertainty. Based on these analyses, the proposed model parameters were estimated with high accuracy. The model was then used to develop a new dose-response model for $S$. aureus using the exponential dose-response model. The new $S$. aureus model has an optimized k parameter equivalent to $8.05 \times 10^{-8}$ with $95^{\text {th }}$ percentile confidence intervals between $6.46 \times 10^{-8}$ and $1.00 \times 10^{-7}$.
\end{abstract}

Keywords: S. aureus; growth and decay; dose-response; Gompertz model; inverse problem

\section{Introduction}

Staphylococcus aureus is a common gram-positive bacterium of clinical significance causing skin and soft-tissue infections worldwide [1,2]. Approximately $10 \%$ to $30 \%$ of the population is estimated to be colonized with $S$. aureus on the skin or in the nose [3]. However, development of antibiotic-resistant strains such as methicillin-resistant $S$. aureus (MRSA) has become a major health concern, especially for hospital settings and community-acquired infections [4,5]. MRSA is often found at higher incidence in healthcare settings as compared to community settings. In a U.K. study, nearly $2 \%$ of patients were colonized after admission [6], while a U.S. study estimates that $4 \%$ of hospital inpatients are colonized [7,8]. Klevens et al. [9] reported about 9000 observed cases of MRSA per year in the U.S., in which $58.4 \%$ were associated with healthcare settings and $26.6 \%$ were community-based. The national burden of MRSA infections in the U.S. in 2014 was about 72,000 infections [10]. The Centers for Disease Control and Prevention Emerging Infections Program (EIP) population-based surveillance from 2009 to 2013 found a total of 4607 nursing-home onset and 4344 hospital-onset cases of invasive MRSA [11].

The anterior nares is the primary reservoir of the $S$. aureus in humans and the replication occurs followed by dispersal of the organism to the skin $[12,13]$. About $30 \%$ of all humans carry S. aureus in 
their nose persistently, while another $20 \%$ to $30 \%$ carry intermittently [14]. The typical transmission route of S. aureus is from the nose to the hand of a person [15], then to a surface (e.g., a door knob), and/or via the hand to the nose of a second person $[16,17]$. Activities involving close physical contact and the risk of minor injuries are positively correlated with S. aureus spread and acquisition [18]. Even a brief contact of fingers with a $S$. aureus contaminated surface may cause the transfer of a large amount of organisms resulting in a potential infection hazard [19]. The transfer rate is higher from moist contaminated surfaces than dry surfaces $[20,21]$.

S. aureus can survive on dry surfaces between 2 and 4 days, and then can be easily transferred to hands and foods [22]. Other experiments showed more than a day of survival in hospital fabrics (cotton, terry, blend, and polyester) to over 90 days of survival in polyethylene [23]. These long survival times indicate a potential high risk of transmission of $S$. aureus through the surface-to-hand pathway. Once $S$. aureus is in the human body, it is believed to form biofilms, which makes the pathogen less vulnerable to host immune responses and allows them to cause colonization and local infections [14].

S. aureus is an opportunistic pathogen and does not usually pose a fatal risk to humans even if it colonizes human mucosa or skin [14]. However, in some cases, S. aureus can cause severe or fatal infections. S. aureus infections progress in five stages: colonization, local infection, systematic dissemination, metastatic infection, and toxinosis [24]. Severe forms of S. aureus infection include bacteremia, sepsis, pneumonia, endocarditis, and osteomyelitis [25]. The causative agent of 50\% of all cutaneous infections is $S$. aureus $[26,27]$. Young children, the elderly population living in poor hygienic conditions, persons with diabetes and overweight conditions, and people living in high temperatures and humid conditions are particularly sensitive to $S$. aureus infection [28].

Quantitative microbial risk assessment (QMRA) is the process of characterizing health risk associated with pathogen exposures through environmental media [29]. QMRA follows a four-step paradigm similar to chemical risk assessment which begins with hazard identification, followed by an exposure assessment to quantify the number of organisms a receptor (i.e., human) comes in contact with based on the fate and transport of the organisms across an exposure pathway (i.e., hand-to-surface-to-mouth). Dose-response models are generally developed from controlled animal or human trials to describe the mathematical relationship between a given exposure dose and the probability of an adverse health outcome (i.e., infection, illness, or death). Such models are quasi-mechanistic in that they are derived from mathematical models that describe the plausibility of biological processes resulting in a measurable health endpoint [30] rather than the deep incorporation of mechanisms of in vivo physiological response. The final step in QMRA integrates the exposure dose prediction with the dose-response model to estimate risks with a characterization of the variability and uncertainty in the predicted values.

For the majority of pathogens with peer-reviewed dose-response models (primarily for ingestion, inhalation, and similar exposure routes), no manipulation of the exposed dose in human and/or animal trials is required to fit a dose-response relationship. Due to the testing procedures used to estimate S. aureus infection-inoculation of the skin followed by occlusion which promotes growth-a transformation of the exposure dose is required prior to modeling the probability of infection [28]. This article describes the development of a S. aureus dose-response model using previously collected peer-reviewed data. The dose-response model is based on a model fit to a previously untested model to describe $S$. aureus growth on skin that captures the S. aureus growth and decay kinetics after inoculation (or exposure) with a low relative error and low correlation among estimated parameters as compared to the previous work in this area [28]. As S. aureus has recently risen to be among the leading causes of hospital-acquired infections, this new dose-response model should be a useful tool in estimating human S. aureus risk in order to support risk management evaluation (e.g., test behavioral changes on risk reduction or surface decontamination strategies). While the best fit parameter of the dose-response model remains unchanged over the previous work, uncertainty bounds around this estimate were desirable and the previous fit of the kinetic model could not be reproduced, thereby generating an opportunity to illustrate the inverse problem parameter estimation approach in a novel context. 


\section{Results and Discussion}

\subsection{Review of the Previous Model}

To evaluate the model developed by Rose and Haas [28], scaled sensitivity coefficients and correlation matrices for all the parameter estimates were created for each of the curves shown in Figure 1. Figure 2 shows the scaled sensitivity coefficients for the first curve (highest initial dose). As can be seen from the figure, the parameters are highly correlated, and after three days, it would be impossible to estimate most of the parameters.
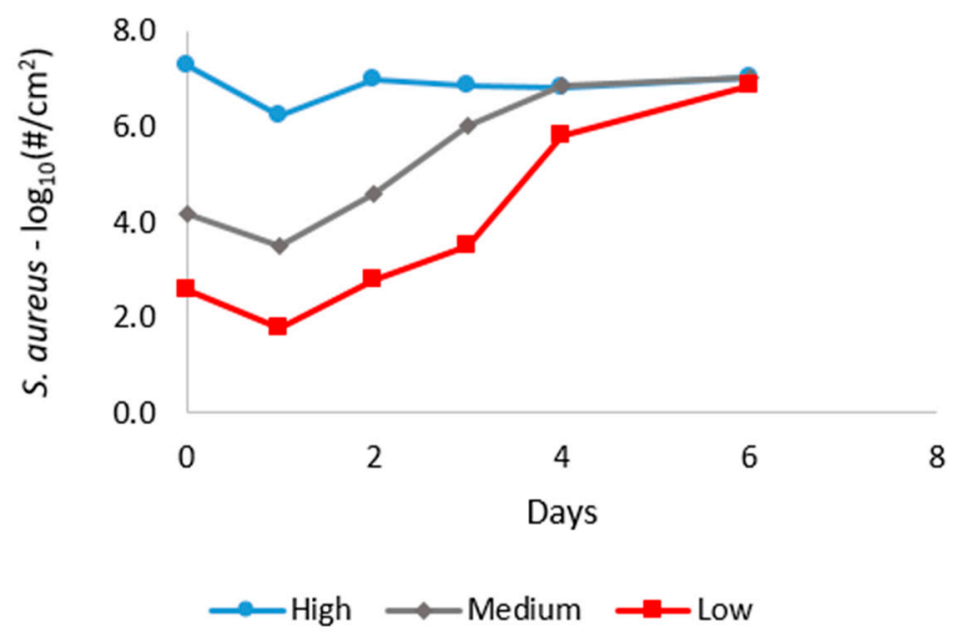

Figure 1. S. aureus growth and decay after inoculation.

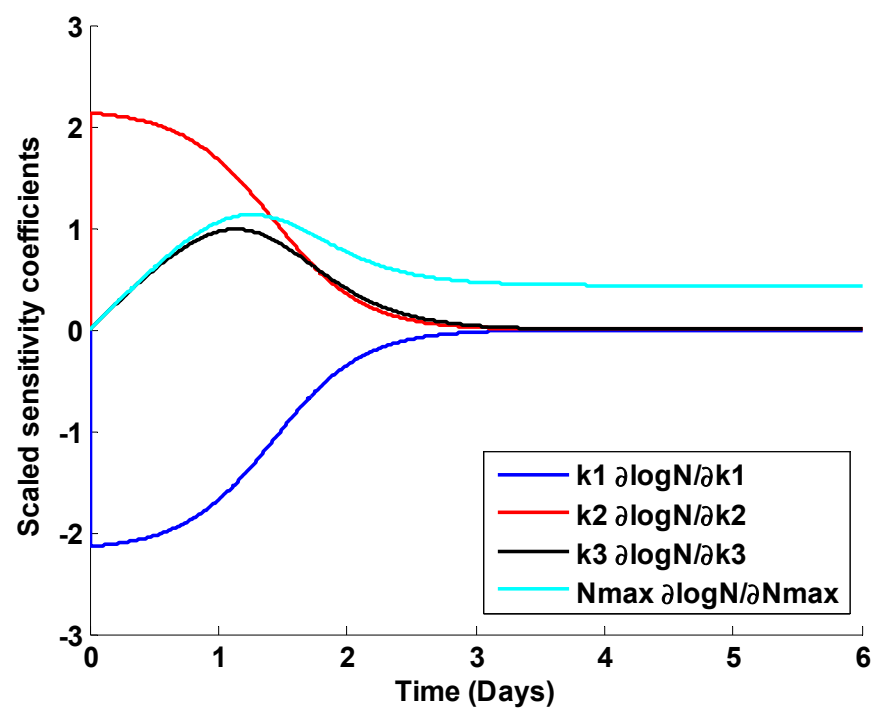

Figure 2. Scaled sensitivity coefficients of the parameter estimates from the first curve (high dose) for the model (Equation (1)) developed by Rose and Haas [28].

Table 1 shows the parameter correlation matrix of the parameter estimate corresponding to the first curve in Figure 1 (highest initial dose). As can be seen from the table, parameters $K_{1}$ and $K_{2}$ are highly correlated, making it hard to estimate the parameters separately. 
Table 1. Correlation matrix of the parameter estimates from Rose and Haas [28].

\begin{tabular}{ccccc}
\hline & $\mathbf{K}_{\mathbf{1}}$ & $\mathbf{K}_{\mathbf{2}}$ & $\mathbf{K}_{\mathbf{3}}$ & $\mathbf{N}_{\max }$ \\
\hline $\mathrm{K}_{1}$ & 1 & \multicolumn{3}{c}{ Symmetric } \\
$\mathrm{K}_{2}$ & 0.9932 & 1 & & \\
$\mathrm{~K}_{3}$ & -0.0392 & -0.0943 & 1 & 1 \\
$\mathrm{~N}_{\max }$ & -0.2894 & -0.2788 & -0.7364 & 1 \\
\hline
\end{tabular}

\subsection{Gompertz Growth and Decay Model}

Various mathematical models has been used to capture the growth kinetics of S. aureus on different food products (i.e., cheese [31]; pork, ham, and sausages [32]; milk [33]; cooked potato and potato salad [34]; rice cake [35]; and sandwiches [36]). In these studies, a modified version of the following three models was used to model S. aureus growth: the Baranyi model [31,35,37]; the logistic model [32-34,38]; and the Gompertz model [36]. In this study, the Gompertz growth/inactivation models were used due to their capability to capture both the growth and decay kinetics of $S$. aureus on human skin (see Figure 3). Additionally, several studies have referred to the Gompertz model adaptively in capturing log-linear kinetics and shoulder and/or tailing effects, which is the case in Singh et al.'s data [39-41].

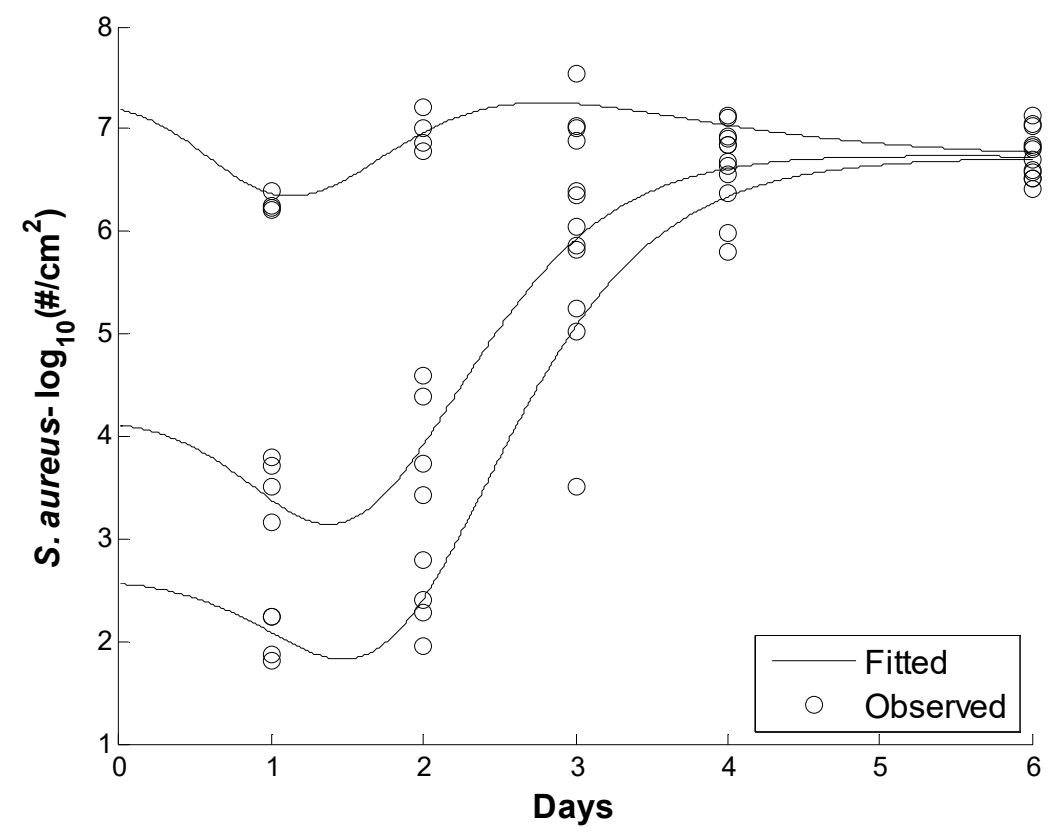

Figure 3. Data and fitted values from the Gompertz growth and decay model.

The results of parameter estimation to estimate S. aureus kinetic parameters are presented in this section. Figure 3 shows the observed and fitted values using the Gompertz growth and decay model. The figure shows that the model was able to capture the growth and decay kinetics of the S. aureus growth data.

Table 2 shows the mean parameter values, 95\% confidence interval, and relative error of the estimated parameters. The results showed that the new model parameters could be estimated with higher confidence and low relative error. 
Table 2. Estimates of parameters with ordinary least square (OLS) and relative errors for the Gompertz model.

\begin{tabular}{ccccc}
\hline Parameters & Estimate & \multicolumn{2}{c}{ 95\% Confidence Interval } & Relative Error (\%) \\
\hline$A$ & 1.00 & 0.94 & 1.05 & 2.63 \\
\hline$\mu$ & 1.02 & 0.80 & 1.25 & 10.95 \\
\hline$M$ & 1.48 & 1.20 & 1.76 & 9.45 \\
\hline$C$ & 6.71 & 6.51 & 6.91 & 1.52 \\
\hline$B$ & 1.47 & 1.25 & 1.69 & 7.48 \\
\hline$\beta 6$ & 2.35 & 2.25 & 2.45 & 2.1 \\
\hline$\beta 7$ & 1.63 & 1.40 & 1.87 & 7.33 \\
\hline
\end{tabular}

The scaled sensitivity coefficient plot shows that the parameters are independent of each other (Figure 4). Based on the absolute value of the scaled sensitivity coefficient plots, the parameters can then be estimated in the following order, from easiest to most difficult, $a, C, \beta 7, M, \mu, B$, and $\beta_{6}$, respectively. (The larger and more uncorrelated scaled sensitivity coefficients indicate computational ease in the estimation of the parameters.)

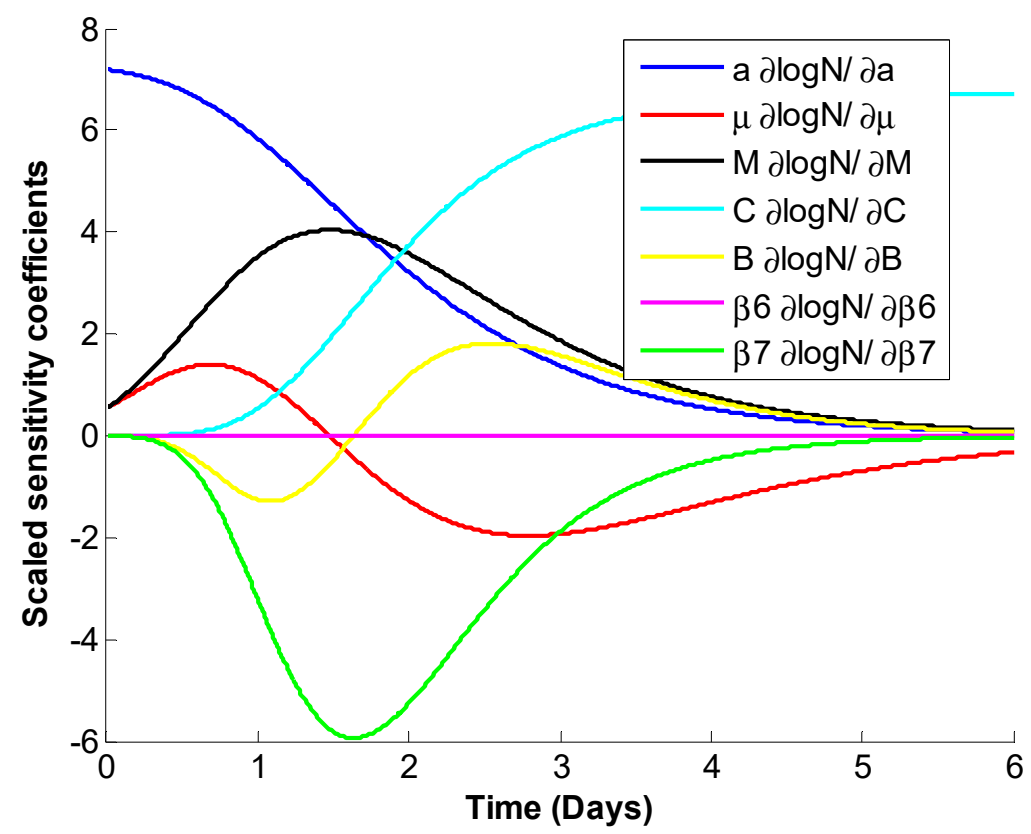

Figure 4. Scaled sensitivity coefficients of the parameters in the new S. aureus growth model (Equations (3) and (4)).

The correlation matrix of parameters is presented in Table 3. A smaller correlation between parameters indicates that parameters are more independent from each other and can be estimated better. The lowest correlation is found between $C$ and $M$, and $B$ and $\beta 7$ with the values of -0.26 and 0.04 , respectively. Among all the parameters, the highest correlation is found between $M$ and $\beta 7$ with a value of 0.85 . 
Table 3. Correlation matrix for the S. aureus growth model parameters.

\begin{tabular}{cccccccc}
\hline & $\boldsymbol{A}$ & $\boldsymbol{\mu}$ & $\mathbf{M}$ & $\mathbf{C}$ & $\mathbf{B}$ & $\boldsymbol{\beta} 6$ & $\boldsymbol{\beta} 7$ \\
\hline $\mathrm{a}$ & 1.00 & & & & & & \\
$\mu$ & -0.42 & 1.00 & & & Symmetric & \\
$\mathrm{M}$ & -0.56 & -0.07 & 1.00 & & & & \\
$\mathrm{C}$ & -0.08 & 0.37 & -0.26 & 1.00 & & & \\
$\mathrm{~B}$ & -0.24 & 0.57 & 0.18 & -0.28 & 1.00 & & \\
$\beta 6$ & -0.07 & -0.37 & 0.51 & -0.04 & -0.13 & 1.00 & \\
$\beta 7$ & -0.19 & -0.34 & 0.85 & -0.26 & 0.04 & 0.53 & 1.00 \\
\hline
\end{tabular}

The estimated values of parameters obtained from OLS, the relative errors, and 95\% confidence intervals for each parameter are given in Table 2. As predicted from Figure 3, the lowest relative error was for $C$ and $\beta 6$, which have the largest scaled sensitivity coefficients. All the parameters have a relative error below $11 \%$. The root mean square error (RMSE) was 0.353 , a low value compared to the total span of $\sim 6 \log$ (Figure 3).

\subsection{Development of a New Dose-Response Model}

Following the development of a new S. aureus growth model, the dose-response data presented in Table 4 were revisited and adjusted. Table 5 presents the revised dose-response data that account for the $S$. aureus growth and decay kinetics for the six days of occluding.

Table 4. S. aureus dose-response data.

\begin{tabular}{ccc}
\hline Initial Dose $\left.\mathbf{( N o .} / \mathbf{c m}^{2}\right)$ & Subjects with Infection & Total Subjects \\
\hline 40 & 4 & 20 \\
\hline 220 & 8 & 20 \\
\hline 2000 & 13 & 20 \\
\hline 105,000 & 14 & 20 \\
\hline $1,600,000$ & 19 & 20 \\
\hline $10,000,000$ & 20 & 20 \\
\hline
\end{tabular}

Table 5. Revised S. aureus dose-response data from Singh et al. [39].

\begin{tabular}{ccc}
\hline Integrated Dose (AUC) $\left(\right.$ Days $\times$ No. $\left./ \mathbf{c m}^{2}\right)$ & Subjects with Infection & Total Subjects \\
\hline $7.32 \times 10^{6}$ & 4 & 20 \\
\hline $8.45 \times 10^{6}$ & 8 & 20 \\
\hline $1.03 \times 10^{7}$ & 13 & 20 \\
\hline $1.59 \times 10^{7}$ & 14 & 20 \\
\hline $2.26 \times 10^{7}$ & 19 & 20 \\
\hline $4.15 \times 10^{7}$ & 20 & 20 \\
\hline
\end{tabular}

Revised doses from Table 4 were fitted into Equation (5) to obtain dose-response parameters. Figure 5 shows the revised doses, fitted model, observed and predicted risks along with the $95 \%$ and $99 \%$ confidence intervals. 


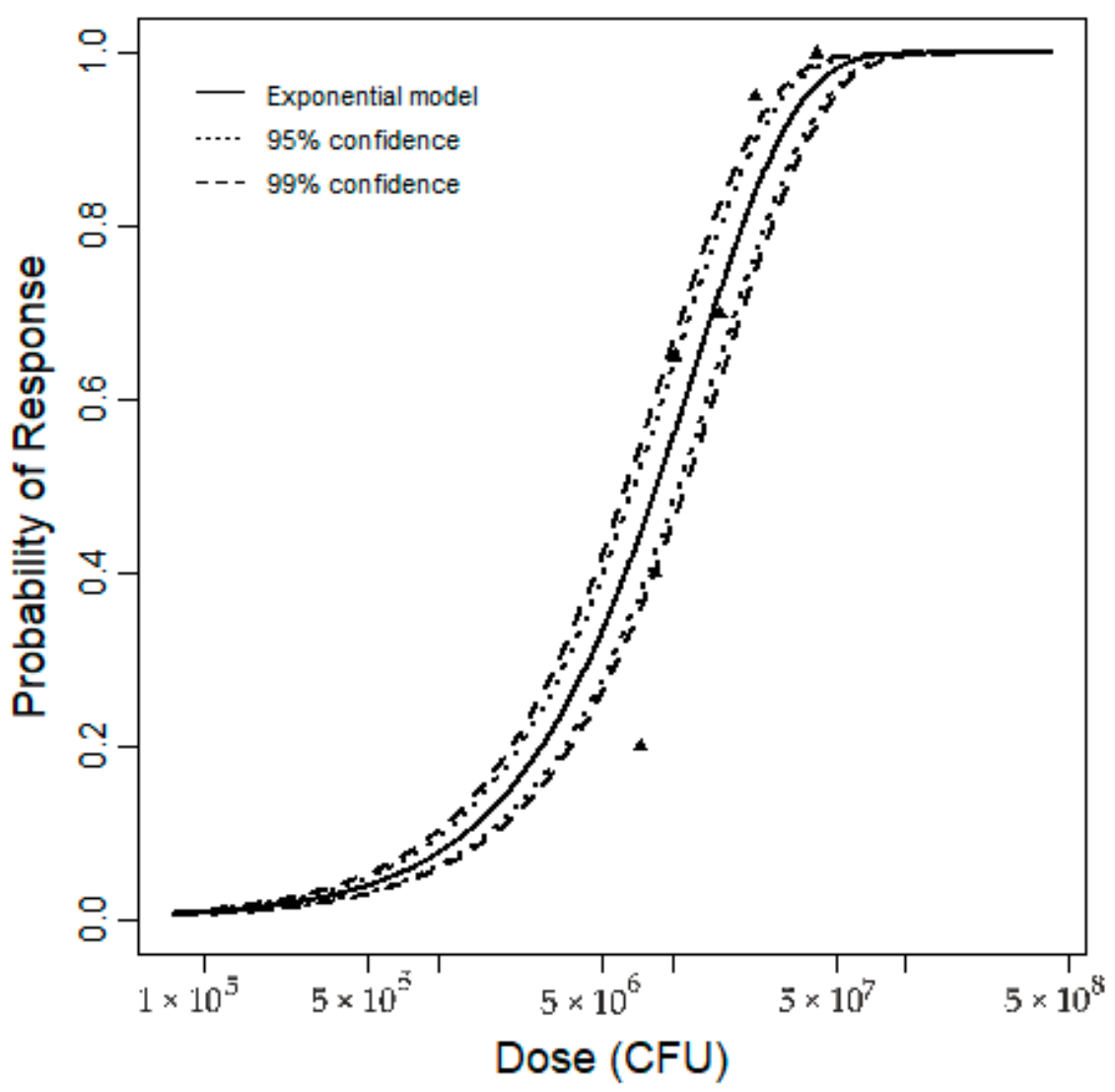

Figure 5. Best-fit dose-response model with $95 \%$ and $99 \%$ confidence intervals.

Table 6 presents the $S$. aureus parameter values for the new dose-response model. The median value (or MLE) estimate was obtained by using the maximum likelihood estimation (MLE) method, and the uncertainty estimates are based on the bootstrapping resampling technique [29]. The best fit parameter, $k$, is equivalent to $8.05 \times 10^{-8}$. The previously published model had a slightly higher $k$ value, which would provide a more conservative estimate of risk.

Table 6. Dose-response model parameters for S. aureus.

\begin{tabular}{cccccccc}
\hline \multirow{2}{*}{ Parameter } & \multirow{2}{*}{ MLE Estimate } & \multicolumn{5}{c}{ Percentiles } \\
\cline { 2 - 7 } & & $\mathbf{0 . 5 \%}$ & $\mathbf{2 . 5 \%}$ & $\mathbf{5 \%}$ & $\mathbf{9 5 \%}$ & $\mathbf{9 7 . 5 \%}$ & $\mathbf{9 9 . 5 \%}$ \\
\hline $\mathrm{k}$ & $8.05 \times 10^{-8}$ & $6.06 \times 10^{-8}$ & $6.46 \times 10^{-8}$ & $6.70 \times 10^{-8}$ & $9.69 \times 10^{-8}$ & $1.00 \times 10^{-7}$ & $1.08 \times 10^{-7}$ \\
\hline
\end{tabular}

\section{Method}

\subsection{Development of the S. aureus Growth Model}

\subsubsection{Data Source}

In this study, data from Singh et al. [39] were used to develop S. aureus growth and decay models. Figure 1 shows the $S$. aureus growth data presented in Singh et al. [39] in which the growth of S. aureus on skin was investigated over 6 days after inoculation. The forearm skin of the human volunteers was initially inoculated with $7.30\left[\log _{10}\left(\# / \mathrm{cm}^{2}\right)\right]\left(\right.$ high), $4.18\left[\log _{10}\left(\# / \mathrm{cm}^{2}\right)\right]$ (medium), and $2.60\left[\log _{10}\right.$ $\left(\# / \mathrm{cm}^{2}\right)$ ] (low) of $S$. aureus bacteria. The bacterial population kinetics of $S$. aureus were measured on 1, 2, 3, 4, and 6 days after application. As presented in Figure 1 in Section 2.1, each curve contains only six observations without any replication. Therefore, to fill the data gaps, three additional random 
data points were generated at each observation. The random points were generated using a normal distribution with a standard deviation of 0.3 .

\subsubsection{Review of the Previous Model}

As a part of the model development process, the previous model developed by Rose and Haas [28] was analyzed. Equation (1) shows the S. aureus model developed by Rose and Haas [28]:

$$
\frac{d N}{d t}=-k_{1} N \exp \left(-k_{2} t\right)-k_{3} N\left(N_{\max }-N\right)
$$

where, $N$ is the microorganism density $\left(\# / \mathrm{cm}^{2}\right), N_{\max }$ is the maximum microorganism density $\left(\# / \mathrm{cm}^{2}\right)$, $k_{1}$ is the initial inactivation rate constant (1/time), $k_{2}$ is the rate constant for the decrease in inactivation (1/time), and $k_{3}$ is the growth rate constant $\left(\mathrm{cm}^{2} / \#\right.$-time). The data were refitted to Equation (1) and the statistical parameters, correlation coefficient, and scaled sensitivity coefficient (see Section 2.1) were analyzed. Results for Equation (1) are shown in Figure 2 (Section 2.1).

\subsubsection{Gompertz Growth and Decay Models}

In order to model S. aureus growth and decay on skin, the Gompertz inactivation model [42] was combined with the Gompertz growth model [43]. Each of these models has three parameters summing up to six parameters. The combined model is as follows:

$$
\log N(t)=\log N(0)\{1-\exp [-\exp (-\mu(t-M))]\}+C \exp \{-\exp [-B(t-L)]\}
$$

where $\log N(t)$ is the microbial concentration at time $t, \log N(0)$ is the initial microbial concentration $\left(\log _{10}\left(\# / \mathrm{cm}^{2}\right)\right), \mu$ is the inactivation rate $\left(\right.$ day $\left.^{-1}\right), t$ is the time (day), $M$ is the lag factor (day), $C$ is the difference between the upper and lower asymptote $\left(\log _{10}\left(\# / \mathrm{cm}^{2}\right)\right), B$ is the growth rate $\left(\right.$ day $\left.^{-1}\right)$, and $L$ is the time at which the inflection point occurs when the growth rate is maximum [41].

At the initial time $(t=0)$, Equation (2) does not equal $\log N(0)$ but rather equals to a multiple of $\log$ $N(0)$. Therefore, a new term, $a$, is introduced as the first parameter instead of $\log N(0)$.

$$
\log N(t)=a \log N(0)\{1-\exp [-\exp (-\mu(t-M))]\}+C \exp \{-\exp [-B(t-L)]\}
$$

where, $a$ is the ratio of $\log N(t)$ to $\log N(0)$ at $t=0$.

Additionally, we noted that the parameter $L$ in Equations (2) and (3) is linearly correlated to $\log$ $N(0)$. Therefore, we developed an empirical linear equation for $L$ with two parameters, called $\beta_{6}$ and $\beta_{7}$, as shown in Equation (4).

$$
L=\frac{\log N(0)_{\max }-\log N(0)}{\log N(0)_{\max }-\log N(0)_{\text {min }}} \beta_{6}+\frac{\log N(0)-\log N(0)_{\text {min }}}{\log N(0)_{\text {max }}-\log N(0)_{\text {min }}} \beta_{7}
$$

where, $\log N(0)_{\text {max }}$ is the maximum initial concentration in Singh et al.'s (1971) data $\left(7.30\left(\log \left(\# / \mathrm{cm}^{2}\right)\right)\right)$, and $\log N(0)_{\text {min }}$ is the minimum initial concentration in Singh data $\left(2.60\left(\log \left(\# / \mathrm{cm}^{2}\right)\right)\right)$. Our hypothesis, based on the data, was that $L$ linearly increased with $\log N(0)$.

\subsubsection{Parameter Estimation Methods}

Ordinary Least Squares Estimation (OLS).

The "nlinfit" command in MATLAB R2013b (Mathworks Inc., Natick, MA) was used to estimate the parameters by minimizing the sum of squares in the model, using the MATLAB nonlinear regression function, nlinfit. Detailed procedures to determine the confidence interval and the correlation matrix of parameters are given by Mishra et al. [44] and Dolan et al. [45]. 


\section{Scaled Sensitivity Coefficients}

Sensitivity coefficients are the first derivative of the model with respect to the parameter. Scaled sensitivity coefficients (SSCs) are the product of each parameter and its sensitivity coefficient, so that the SSC units are the same as those of the model. The SSCs visualize the sensitivity of the model to each parameter, and the dependency of parameters on each other in the model [41]. Larger and more uncorrelated scaled sensitivity coefficients indicate easier estimation of those parameters. A forward finite- difference method was used to compute the scaled sensitivity coefficients.

\subsection{Development of the S. aureus Dose-Response Model}

\subsubsection{Data Source}

Dose-response data were also obtained from Singh et al. [39]. The 20 test subjects were inoculated with six different doses of S. aureus and occluded for six days. Skin infection, which Singh et al. [39] described as "takes", was appraised after six days. Table 4 shows the dose-response data after six days (see Section 2.3).

\subsubsection{Revised S. aureus Dose}

As Singh et al. [39] reported, there was S. aureus growth over the six-day period. Hence, the initial inoculation, as shown in Table 1, cannot be used as the dose. Therefore, Equation (3) was used to estimate the $S$. aureus growth over the six-day period. Initial doses presented in Table 4 were revised by calculating the area under the curve (AUC) for each day and summing up the dose for six days (see Table 5, Section 2.3).

\subsubsection{Fitting Dose-Response Model and Uncertainty Analysis}

The revised data were used to fit the exponential dose-response model as shown in Equation (5).

$$
P(\text { response })=1-\exp (-k \times \text { dose })
$$

where $P$ (response) is the risk of infection, $k$ is the dose-response function parameter representing the probability that the organism survives to initiate infection $\left(\mathrm{CFU}^{-1}\right)$, and dose is the exposure dose (CFU).

The model was fit in the R package (The R Project for Statistical Computing, r-project.org) using a maximum likelihood estimation (MLE). Confidence intervals were estimated using a bootstrapping technique, which provides a description of the uncertainty in the parameter estimated [29].

\section{Conclusions}

This study describes the development of a predictive microbial kinetic model to capture S. aureus growth and decay on human skin and a new fit of the $S$. aureus dose-response model which can be used to characterize the risk of infection through quantitative microbial risk assessment (QMRA) [29]. To our knowledge, it is the first study to use an inverse problem approach to estimate $S$. aureus kinetic parameters. The results indicate that the proposed model is highly capable of predicting S. aureus kinetics on human skin. The model parameters were easier to estimate and had lower relative error than those in Equation (1) (the Rose and Haas model [28]). This study also demonstrates that the inverse problem is a convenient approach in estimating the kinetic parameters of $S$. aureus on skin. The kinetic model developed would need to be modified in order to be used for other hosts (i.e., animals and food products). The newly developed kinetic model was also used to predict $S$. aureus growth in order to estimate the dose on the skin that produced observed infections in order to develop a new dose-response model. The new dose-response model and parameters can be useful to estimate the risk of human skin infection as the result of dermal contact with S. aureus. 
Author Contributions: Conceptualization, J.M.; Formal analysis, E.E. and U.A.; Investigation, U.A.; Methodology, K.D.; Project administration, J.M.; Supervision, J.M.; Writing - original draft, E.E.; Writing - review \& editing, U.A. and J.M.

Funding: This research received no external funding.

Acknowledgments: The authors would like to thank Kara Dean for her technical review and quality control check of the modeling work in this paper.

Conflicts of Interest: The authors declare no conflict of interest.

\section{References}

1. Lowy, F.D. Staphylococcus aureus infections. N. Engl. J. Med. 1998, 339, 520-532. [CrossRef] [PubMed]

2. Tseng, C.W.; Biancotti, J.C.; Berg, B.L.; Gate, D.; Kolar, S.L.; Müller, S.; Rodriguez, M.D.; Rezai-Zadeh, K.; Fan, X.; Beenhouwer, D.O.; et al. Increased susceptibility of humanized NSG mice to Panton-Valentine leukocidin and Staphylococcus aureus skin infection. PLoS Pathog. 2015, 11, e1005292. [CrossRef] [PubMed]

3. Verbrugh, H.A. Colonization with Staphylococcus aureus and the role of colonization in causing infection. In Staphylocci in Human Disease; Crossley, K.B., Jefferson, K.K., Archer, G.L., Fowler, V.G., Jr., Eds.; Wiley-Blackwell: Chichester, UK, 2009; pp. 255-271.

4. Ryan, M.O.; Haas, C.N.; Gurian, P.L.; Gerba, C.P.; Panzl, B.M.; Rose, J.B. Application of quantitative microbial risk assessment for selection of microbial reduction targets for hard surface disinfectants. Am. J. Infect. Control 2014, 42, 1165-1172. [CrossRef] [PubMed]

5. Peacock, S.J.; Paterson, G.K. Mechanisms of methicillin resistance in Staphylococcus aureus. Annu. Rev. Biochem. 2015, 84, 577-601. [CrossRef] [PubMed]

6. Krebes, J.; Al-Ghusein, H.; Feasey, N.; Breathnach, A.; Lindsay, J.A. Are nasal carriers of Staphylococcus aureus more likely to become colonized or infected with methicillin-resistant Staphylococcus aureus on admission to a hospital? J. Clin. Microbiol. 2011, 49, 430-432. [CrossRef]

7. Jarvis, W.R.; Jarvis, A.A.; Chinn, R.Y. National prevalence of methicillin-resistant Staphylococcus aureus in inpatients at United States health care facilities, 2010. Am. J. Infect. Control 2012, 40, 194-200. [CrossRef]

8. Lindsay, J.A. Staphylococcus aureus genomics and the impact of horizontal gene transfer. Int. J. Med. Microbiol. 2014, 304, 103-109. [CrossRef]

9. Klevens, R.M.; Morrison, M.A.; Nadle, J.; Petit, S.; Gershman, K.; Ray, S.; Harrison, L.H.; Lynfield, R.; Dumyati, G.; Townes, J.M.; et al. Invasive methicillin-resistant Staphylococcus aureus infections in the United States. JAMA 2007, 298, 1763-1771. [CrossRef]

10. See, I.; Mu, Y.; Albrecht, V.; Karlsson, M.; Dumyati, G.; Hardy, D.J.; Koeck, M.; Lynfield, R.; Nadle, J.; Ray, S.M.; et al. Trends in incidence of methicillin-resistant Staphylococcus aureus bloodstream infections differ by strain type and healthcare exposure, United States, 2005-2013. Clin. Infect. Dis. 2019. [CrossRef]

11. Grigg, C.; Palms, D.; Stone, N.D.; Gualandi, N.; Bamberg, W.; Dumyati, G.; Harrison, L.H.; Lynfield, R.; Nadle, J.; Petit, S.; et al. Burden of Invasive Methicillin-Resistant Staphylococcus Aureus Infections in Nursing Home Residents. J. Am. Geriatr. Soc. 2018. [CrossRef]

12. Kluytmans, J.; Van Belkum, A.; Verbrugh, H. Nasal carriage of Staphylococcus aureus: Epidemiology, underlying mechanisms, and associated risks. Clin. Microbiol. Rev. 1997, 10, 505-520. [CrossRef] [PubMed]

13. Decker, C.F. Pathogenesis of MRSA infections. Dis. Mon. 2008, 54, 774-779. [CrossRef] [PubMed]

14. Van Wamel, W.J. Staphylococcus aureus infections, some second thoughts. Curr. Opin. Infect. Dis. 2017, 30, 303-308. [CrossRef] [PubMed]

15. Wertheim, H.F.; Van Kleef, M.; Vos, M.C.; Ott, A.; Verbrugh, H.A.; Fokkens, W. Nose picking and nasal carriage of Staphylococcus aureus. Infect. Control Hosp. Epidemiol. 2006, 27, 863-867. [CrossRef] [PubMed]

16. Byrne, F.M.; Wilcox, M.H. MRSA prevention strategies and current guidelines. Injury 2011, 42, S3-S6. [CrossRef]

17. Sollid, J.U.E.; Furberg, A.S.; Hanssen, A.M.; Johannessen, M. Staphylococcus aureus: Determinants of human carriage. Infect. Genet. Evol. 2014, 21, 531-541. [CrossRef]

18. Kazakova, S.V.; Hageman, J.C.; Matava, M.; Srinivasan, A.; Phelan, L.; Garfinkel, B.; Boo, T.; McAllister, S.; Anderson, J.; Jensen, B. A clone of methicillin-resistant Staphylococcus aureus among professional football players. N. Engl. J. Med. 2005, 352, 468-475. [CrossRef] 
19. Scott, E.; Bloomfield, S.F. Investigations of the effectiveness of detergent washing, drying and chemical disinfection on contamination of cleaning cloths. J. Appl. Bacteriol. 1990, 68, 279-283. [CrossRef]

20. Marples, R.R.; Towers, A.G. A laboratory model for the investigation of contact transfer of micro-organisms. Epidemiol. Infect. 1979, 82, 237-248. [CrossRef]

21. Sattar, S.A.; Springthorpe, S.; Mani, S.; Gallant, M.; Nair, R.C.; Scott, E.; Kain, J. Transfer of bacteria from fabrics to hands and other fabrics: Development and application of a quantitative method using Staphylococcus aureus as a model. J. Appl. Microbiol. 2001, 90, 962-970. [CrossRef]

22. Kusumaningrum, H.D.; Paltinaite, R.; Koomen, A.J.; Hazeleger, W.C.; Rombouts, F.M.; Beumer, R.R. Tolerance of Salmonella enteritidis and Staphylococcus aureus to surface cleaning and household bleach. J. Food Prot. 2003, 66, 2289-2295. [CrossRef] [PubMed]

23. Neely, A.N.; Maley, M.P. Survival of enterococci and staphylococci on hospital fabrics and plastic. J. Clin. Microbiol. 2000, 38, 724-726. [PubMed]

24. Archer, G.L. Staphylococcus aureus: A well-armed pathogen. Rev. Infect. Dis. 1998, 26, 1179-1181. [CrossRef] [PubMed]

25. CDC. Staphylococcus aureus in Healthcare Settings; Centers for Disease Control and Prevention: Atlanta, GA, USA, 2011. Available online: https://www.cdc.gov/hai/organisms/staph.html (accessed on 19 September 2017).

26. Cohen, J.; Pinching, A.J.; Rees, A.J.; Peters, D.K. Infection and immunosuppression: A study of the infective complications of 75 patients with immunologically-mediated disease. QJM: Int. J. Med. 1982, 51, 1-15.

27. Finkey, M.B.; Corbin, N.C.; Aust, L.B.; Aly, R.; Maibach, H.I. In vivo effect of antimicrobial soap bars containing $1.5 \%$ and $0.8 \%$ trichlorocarbanilide against two strains of pathogenic bacteria. J. Soc. Cosmet. Chem. 1984, 35, 351-355.

28. Rose, J.B.; Haas, C.N. A risk assessment framework for the evaluation of skin infections and the potential impact of antibacterial soap washing. Am. J. Infect. Control 1999, 27, S26-S33. [CrossRef]

29. Haas, C.; Gerba, C.; Rose, J.B. Quantitative Microbial Risk Assessment; Wiley: New York, NY, USA, 2014.

30. Haas, C.N. Microbial dose response modeling: Past, present, and future. Environ. Sci. Technol. 2015, 49, 1245-1259. [CrossRef]

31. Lee, H.; Kim, K.; Lee, S.; Han, M.; Yoon, Y. Growth kinetics of Staphylococcus aureus on Brie and Camembert cheeses. J. Dairy Res. 2014, 81, 252-256. [CrossRef]

32. Mansur, A.R.; Park, J.H.; Oh, D.H. Predictive model for growth of staphylococcus aureus on raw pork, ham, and sausage. J. Food Prot. 2016, 79, 132-137. [CrossRef]

33. Fujikawa, H.; Morozumi, S. Modeling Staphylococcus aureus growth and enterotoxin production in milk. Food Microbiol. 2006, 23, 260-267. [CrossRef]

34. Huang, L. Growth of Staphylococcus aureus in Cooked Potato and Potato Salad-A One-Step Kinetic Analysis. J. Food Sci. 2015, 80, M2837-M2844. [CrossRef] [PubMed]

35. Wang, J.; Koseki, S.; Chung, M.J.; Oh, D.H. A Novel Approach to Predict the Growth of Staphylococcus aureus on Rice Cake. Front. Microbiol. 2017, 8, 1140. [CrossRef] [PubMed]

36. Ding, T.; Shim, Y.H.; Choi, N.J.; Ha, S.D.; Chung, M.S.; Hwang, I.G.; Oh, D.H. Mathematical modeling on the growth of Staphylococcus aureus in sandwich. Food Sci. Biotechnol. 2010, 19, 763-768. [CrossRef]

37. Baranyi, J.; Roberts, T.A. A dynamic approach to predicting bacterial growth in food. Int. J. Food Microbiol. 1994, 23, 277-294. [CrossRef]

38. Pearl, R. The growth of populations. Quart. Rev. Biol. II 1927, 4, 532-548. [CrossRef]

39. Singh, G.; Marples, R.R.; Kligman, A.M. Experimental Staphylococcus aureus infections in humans. J. Investig. Dermatol. 1971, 57, 149-162. [CrossRef]

40. Gil, M.M.; Miller, F.A.; Brandao, T.R.; Silva, C.L. On the use of the Gompertz model to predict microbial thermal inactivation under isothermal and non-isothermal conditions. Food Eng. Rev. 2011, 3, 17-25. [CrossRef]

41. Dolan, K.D.; Mishra, D.K. Parameter estimation in food science. Annu. Rev. Food Sci. Technol. 2013, 4, 401-422. [CrossRef]

42. Huang, L. Thermal inactivation of Listeria monocytogenes in ground beef under isothermal and dynamic temperature conditions. J. Food Eng. 2009, 90, 380-387. [CrossRef]

43. McKellar, R.C.; Lu, X. (Eds.) Modeling Microbial Responses in Food; CRC Press: Boca Ranto, FL, USA, 2003. 
44. Mishra, D.K.; Dolan, K.D.; Yang, L. Confidence intervals for modeling anthocyanin retention in grape pomace during nonisothermal heating. J. Food Sci. 2008, 73, E9-E15. [CrossRef]

45. Dolan, K.D.; Yang, L.; Trampel, C.P. Nonlinear regression technique to estimate kinetic parameters and confidence intervals in unsteady-state conduction-heated foods. J. Food Eng. 2007, 80, 581-593. [CrossRef]

(C) 2019 by the authors. Licensee MDPI, Basel, Switzerland. This article is an open access article distributed under the terms and conditions of the Creative Commons Attribution (CC BY) license (http://creativecommons.org/licenses/by/4.0/). 